\title{
Watershed Pollution and Preservation: The Awareness-Appraisal Model of Environmentally Positive Intentions and Behaviors
}

\author{
Donelson R. Forsyth* \\ Virginia Commonwealth University \\ Margot Garcia \\ Virginia Commonwealth University
}

\section{Linda E. Zyzniewski}

Virginia Commonwealth University

\author{
Paul A. Story \\ Virginia Commonwealth University
}

\author{
Natalie A. Kerr \\ James Madison University
}

A two-factor awareness-appraisal model suggests that individuals' reactions to threatening circumstances are shaped by their awareness of the threat and their appraisal of the degree of threat the circumstances pose to them. This approach, applied to watershed conservation, predicts that individuals will be willing to clean up the rivers and streams of their watershed if they are familiar with local water features (rivers, streams, ponds, lakes) and if they consider these features of the watershed to be degraded. We tested the model by measuring watershed

\footnotetext{
* Correspondence concerning this article should be addressed to Donelson R. Forsyth, Department of Psychology, Virginia Commonwealth University, 810 W. Franklin Street, Richmond, VA 232842018. [e-mail: jforsyth@vcu.edu].

This research was supported by National Science Foundation Grant 9874924. The authors thank the members of the Upham Brook Watershed Group (Diane Dunaway, Gregory Garman, Mort Gulak, Neil Henry, Paddy Katzen, Jennifer Meredith, Joe Mitchel, John Moeser, Susan Ridout, Bob Rugg, Len Smock, Gary Sperian, and Lucy Wysong) for their many contributions to this research. We also appreciate comments on an earlier draft offered by Kelli Taylor.
} 
knowledge, appraisal of watershed quality, value assigned to protecting the watershed, and behavioral intentions regarding watershed preservation in a survey of 1,128 residents of two urban watersheds. The results supported the awarenessappraisal model: Those residents who were aware of their watershed and considered it polluted expressed the strongest pro-preservation behavioral intentions. These relationships were held in both watersheds, but were stronger for those who resided in the more degraded watershed.

Watersheds are natural features of the earth's surface: geographic regions where the water from rain or melting snow flows downhill to rivers and oceans. The hydrological cycle of rainfall, runoff, and evaporation naturally filters the earth's waters, but as watersheds become increasingly urbanized, their capacity to purify decreases significantly. Industries and sewage treatment facilities located in urban areas often release pollutants directly into the watershed's streams and rivers (point source pollution), but runoff from gardens, yards, and city streets also carries trash, soil, and other pollutants through the watershed (nonpoint source pollution). Water serves so many needs for people-irrigation of crops, recreation, preparation of food, drinking and bathing, and transportation - that polluted rivers and streams of a watershed can threaten the livelihoods and health of the residents who live in the watershed and those who drink the water that runs through it. Water pollution can also affect natural biological systems, causing unsafe levels of organic residues and metals to build up in fish and other marine life. Pollution can disrupt the chemical and nutritional qualities of waters leading to a loss of oxygen needed by marine life, and changes in the areas around streams and rivers (riparian zones) can result in erosion, flooding, and loss of habitat. The Environmental Protection Agency, Inland Waterways Commission, the National Conservation Commission, and the National Waterways Commission all propose management of water resources at a watershed level (Adler, 1995).

The current project examined individuals' willingness to protect and enhance the quality of the watershed where they live. It assumes that a number of social and psychological factors motivate and retard environmentally responsible behavior, but this investigation focuses on two of these factors: awareness and appraisal. Individuals who are aware of environmental problems and consider them severe will report higher levels of behavioral intentions toward environmentally responsible behavior than individuals who are ambivalent or unaware of such problems. We examined this assumption by surveying residents' awareness and appraisals of their local watershed, which was either clean or degraded, as well as their behavioral intentions with regard to safeguarding the watershed.

\section{Watersheds and Awareness}

Most cognitive models of individuals' goals and their reactions to life events presume that human beings are rational creatures who make systematic use of the 
information available to them and that their actions are under volitional control. Such models assume that individuals' actions are generally based on their attitudes, values, or beliefs pertaining to desirable goals. So by identifying knowledge, attitudes, and desired outcomes, behavior across situations related to those goals can often be predicted.

This general cognitive outlook explains why individuals, in many cases, do not take steps to sustain and protect their environment: they do not have enough information about the environment and its condition to guide their actions. Researchers in many countries have repeatedly found that citizens are not very well informed about the quality of their drinking water or the overall health of the water bodies in their local watersheds. For example, Kasapoglu and Ecevit (2002), in a study of Turkish citizen's perceptions of Lake Burdur and its wetlands, found that few respondents knew anything about the pollution problems with the lake. Case studies of contaminated water bodies, such as the Pigeon River in the United States, also reveal that citizenry are often either apathetic or profoundly uninformed about environmental problems (Bartlett, 1995; Soliman, 1996). A survey of U.S. citizens' environmental knowledge conducted by the National Environmental Education and Training Foundation each year since 1992 consistently finds the majority of Americans fail a short 12-item test of basic environmental knowledge, where a passing score is set at $60 \%$ correct. Only a small percentage of the poll's respondents realize, for example, that runoff from farm fields, roads, parking lots, and lawns is the most common source of water pollution in the United States (NEETF, 1999).

This relative ignorance about environmental issues may translate into a lack of responsiveness to environmental threats. Kasapoglu and Ecevit (2002) report that individuals who had little knowledge of the environmental problems in a wetland area were less likely to report having engaged in some form of environmentally responsible behavior. Soliman (1996) found that few residents pressured civil authorities to regulate pollution of the Pigeon River because it was located in a remote area rather than a highly populated area. Individuals who have little knowledge of the environment and ecosystems are less likely to report pro-environmental attitudes or to have engaged in environmentally responsible behaviors (NEETF, 1999).

However, general knowledge about environmental issues is not always sufficient to prompt action. For example, Gould's (1993) sampling of U.S. and Canadian residents living near six different contaminated water bodies found that awareness alone was not enough for local mobilization. Similarly, Finger (1994) was not able to predict variations in pro-environmental action from Swiss citizens' environmental information and knowledge. Instead, individuals' information pertaining to the environment must indicate that the environment is threatened, degraded, or endangered in some way. Van Vugt and Samuelson (1999), in a study of water conservation during a period of drought, found that individuals were more likely 
to restrict their water use if they were aware of the water shortage and believed that the shortage was severe. Baldassare and Katz (1992), in a survey of California residents, report that individuals were more likely to engage in positive environmental actions, including water conservation, if they knew about environmental issues and believed that these problems could affect them personally. Lubell's (2002) study of the Peconic Bay watershed in New York found that individuals reported higher levels of activism behaviors and intentions when they rated their area as more polluted and contaminated.

These studies suggest that knowledge of the environment is a necessary, but not sufficient, condition for environmentally positive action. Hence, to understand individuals' willingness to engage or not engage in environmentally responsible behavior, we must examine both their awareness and appraisal of the environmental problem. This emphasis on both awareness and appraisal is consistent with studies of individuals' reactions to stressful life circumstances, as identified in Lazarus and Folkman's cognitive appraisal model of stress (Folkman \& Lazarus, 1988; Lazarus \& Folkman, 1984; Smith, 1991). These investigators find that the impact of illnesses, accidents, traumas, frustrations, and other negative life events on health and well-being depends, in part, on awareness and appraisal of the event. Their model suggests that individuals do not respond to stressful events if they do not even notice the event-in many cases individuals do not respond to negative life events simply because they are not aware of these events' impact on them. Once the event is noted, then individuals estimate the magnitude of the threat and their ability to cope with the event.

Applied to reactions to environmental action, an awareness-appraisal model suggests that the first cognitive response, awareness, occurs when individuals notice the features of the natural environment. People will not take actions to correct problems if they never take notice of the streams, rivers, ponds, and other water bodies in their community (Kasapoglu \& Ecevit, 2002; Soliman, 1996). However, as the awareness-appraisal model suggests, awareness alone is not sufficient to take action; individuals must also believe there is a significant environmental problem. They must, by considering presence or absence of such indicators of pollution as trash, surface foam, and industrialization, conclude that the watershed is polluted or degraded (Wilson et al., 1995). As Hungerford and Volk's (1990) model of environmental education notes, "knowledge of ecology does not, in itself, produce environmental behavior" (p. 11). However, an individual with knowledge of ecology who also possesses an in-depth knowledge of the state of the environment will be "inclined to take on citizenship responsibility toward those issues" (p. 12).

\section{The Current Study}

We tested the awareness-appraisal model by surveying the residents of an urban watershed located in Richmond, Virginia, in the United States. This 
watershed lies at the interface of a declining inner city and growth-oriented county with aging suburbs. The area includes two watershed areas: the James River watershed and the Upham Brook watershed. The James River is a prominent feature of the urban area we studied, for this large river cuts through the center of the city and is bridged at a number of visible locations. The streams and brooks of the Upham Brook watershed area, in contrast, are smaller and flow through heavily developed neighborhoods and into the lesser known Chickahominy River. We therefore predicted that the Upham Brook watershed would be less salient to residents, and that they would be more likely to make mistakes when identifying its boundaries and condition. Ironically, the last 5 miles of Upham Brook have been classified as impaired and do not meet quality standards for fishable or swimmable waters. This classification is based on the high fecal coliform levels and low dissolved oxygen levels in the water. Prior efforts to galvanize the community and local government have generated little in the way of active intervention.

The awareness-appraisal model predicts that individuals' willingness to become involved in watershed cleanup is related to their awareness and perceptions of the watershed itself. We assumed that individuals who were familiar with streams, brooks, and creeks in the watershed would express more pro-environment behavioral intentions, but that individuals' intentions would be the most positive when experience with the watershed convinced them that action was needed. In other words, residents who were aware of their local watershed and considered it degraded would have the highest intentions in becoming involved in watershed preservation.

\section{Method}

\section{Participants}

Participants were all residents of the Greater Richmond Metropolitan Area, located in the Commonwealth of Virginia. This geographical area is located in the Chesapeake watershed area of the United States, but it straddles two subwatershed areas: the James River Watershed and the Upham Brook Watershed. Whereas the James River Watershed is relatively unpolluted, portions of the Upham Brook Watershed where the participants resided are identified as impaired by the State of Virginia. The respondents included 479 men and 652 women. They ranged in age from 18 to 99 years, with an average age of 44.4 years. Specifically, $23.6 \%$ were 18-29 years, $37.1 \%$ were $30-44$ years, $29.7 \%$ were $45-64$ years, and $9.6 \%$ reported being 65 years or older. The majority (58.8\%) reported their race as Anglo or White, 33.6\% African American, 1.4\% Asian, and the remainder reported another racial category or did not respond, and these proportions are roughly equivalent to the distribution of such groups in the U.S. Census data. Most (95.6\%) indicated they were not of Hispanic or Spanish origin. Nearly half $(47.12 \%)$ of the 
respondents reported being married, with $18.4 \%$ divorced, widowed, or separated, and $34.5 \%$ single. The majority of the watershed area sample $(52.0 \%)$ had completed high school and some college; over one third (37.9\%) were college graduates, and $16 \%$ did not have a high school diploma. They were primarily employed full time $(66.2 \%)$ with $8.2 \%$ employed part time, and $11.8 \%$ retired. The sample included 133 respondents who lived in the smaller Upham Brook Watershed area, as identified by their zip code reports.

\section{Procedure}

We contacted a sample of residents in the city of Richmond and the surrounding counties by telephone and asked them a series of questions concerning their perceptions of their community and the watershed. The sample was gathered using a random digit dial procedure that included listed and unlisted numbers in the Greater Richmond Metropolitan Area. The poll was conducted by the Survey and Evaluation Research Laboratory of Virginia Commonwealth University. ${ }^{1}$

Measures of watershed perceptions and attitudes. Five items were used to measure residents' (a) awareness of the watershed; (b) perceptions of the quality of watershed streams and brooks; (c) evaluation of watershed protection and maintenance; (d) behavioral intentions regarding watershed protection; and (e) the accuracy of their beliefs about their local watershed (can they correctly identify where the runoff water flows from their neighborhood?). The items were prefaced by the following 3 -sentence introduction to the issue.

The next questions concern the land and streams where you live. Before people built communities in this area of Virginia many streams, creeks, and brooks crisscrossed the land. Some of these streams are still here, but others have been replaced by man-made waterways like drainage ditches and underground pipes. We want to know your opinion of these natural and man-made waterways.

The introduction and items were extensively pretested prior to administration. Draft items were evaluated both by researchers who had studied environmental issues extensively and experts in public opinion polling. A preliminary version of

\footnotetext{
${ }^{1}$ The individual who answered the phone was asked if he or she would be willing to participate in a study "with citizens of the Richmond area concerning some issues that might affect them." If a male who was 18 years or older was at the number, the interviewer asked to speak to him. If no male was available, the interviewer asked to speak to the oldest female, 18 years or older, who was currently home. All subjects were told that their responses were confidential, and they did not have to answer any question they did not want to. The response rate, calculated according to rules set out by the Council of American Survey Research Organizations (CASRO), was 53\%. This is the number of completions divided by the sum of two numbers: (a) number of telephone numbers known to be eligible, and (b) an estimate of the number of phone numbers thought to be eligible among those where eligibility could not be determined (this "unknown eligibility" pool is primarily no answers, answering machines, and busy signals). Numbers that did not answer were contacted 10 to 15 times before the number was abandoned from the sample.
} 
the instrument was then tested with a telephone sample. This field testing indicated that respondents were not familiar with the concept of a watershed. They were not certain what a watershed was, and they did not know the name of the watershed where their residence was located. In consequence, they could not answer general questions about watersheds, such as "what is the quality of the watershed where you live." The items were therefore rewritten so they referred to rivers, streams, and waterways in respondents' residential areas rather than watersheds in general.

The initial question assessed watershed awareness by asking "Do you know of any stream or brook that runs in your neighborhood?" Those respondents who answered in the affirmative were then asked to provide an appraisal of the watershed's water: "What condition is the stream or brook in? Would you say it is clean or not clean?" All participants were then asked about their overall values pertaining to water pollution with the question: "Do you personally think it is important to keep the streams, ditches, and waterways in your area clean and unpolluted?" and the interviewer read them the list of possible responses: very important, somewhat important, or not important. Their behavioral intentions with respect to watershed cleanup activities were then measured with the question "Would you be willing to get involved in helping clean up the creeks and streams where you live?" and they were offered the following series of answers: definitely willing (5), probably willing (4), maybe willing (3), probably not willing (2), or definitely not willing (1).

The final question in this series sought to test the accuracy of respondents' knowledge of their local watershed. Since pretesting of the items indicated that many residents of the Upham Brook Watershed mistakenly believed that their water flowed directly into the James River rather than the Upham Brook/Chickahominy, all respondents were asked the following question: "When it rains the water runs off the roofs, yards, and streets where you live. Into which river does the water flow?" Their free responses were coded as James River, Upham Brook/Chickahominy, some other destination, or don't know.

\section{Results}

As noted in detail in the description of the methods very few of the residents sampled were familiar with the meaning of the concept of a watershed. This lack of familiarity made it necessary to avoid the use of this term in the survey itself, which instead, focused on the overall level of awareness of features of the watershed, such as streams and brooks, as well as the accuracy of their description of the drainage of the area where they live. We then examined the predictions of the awareness-appraisal model to determine if individuals who were both aware of the condition of their watershed and believed that watershed was endangered would report more pro-environmental behavioral intentions. Due to the unequal number of residents in the larger and smaller watershed areas, least squares analyses 
of variances (ANOVA) were used that adjusted each effect for all other effects in the model.

\section{Awareness of the Local Watershed}

Table 1 summarizes respondents' awareness, appraisals, and intentions regarding the watershed and watershed pollution. This table presents the percentage of agreement with each survey item for the entire sample, as well as the percentages within each watershed area. These percentages indicate that, in general, individuals who reside in the impaired watershed, relative to those who live in an unpolluted area, are neither no more aware nor more negative in their appraisals of the condition of their watershed.

Awareness: Do you know of any stream or brook that runs in your neighborhood? Because pretesting indicated that the respondents in the area to be sampled were not familiar with the concept of a watershed, they were asked questions that referred only to the water features of their neighborhood (streams and brooks). However, despite the fact that streams flow throughout the watershed where the

Table 1. Percentage of Participants in Each Response Category on Items Pertaining to Awareness, Appraisals, Values, Behavioral Intentions, and Knowledge of the Local Watershed for Residents of the James Watershed and the Upham Brook Watershed

\begin{tabular}{|c|c|c|c|}
\hline & \multicolumn{3}{|c|}{ Respondent's Watershed Area } \\
\hline & Combined & James & Upham \\
\hline \multicolumn{4}{|l|}{ Awareness } \\
\hline Not aware & 63.0 & 63.5 & 59.4 \\
\hline Aware & 36.4 & 35.9 & 40.6 \\
\hline Don't know & 0.1 & 0.1 & 0.0 \\
\hline \multicolumn{4}{|l|}{ Appraisal } \\
\hline Clean & 59.8 & 60.7 & 53.7 \\
\hline Not clean & 31.1 & 30.2 & 37.0 \\
\hline Don't know & 9.1 & 9.1 & 9.3 \\
\hline \multicolumn{4}{|l|}{ Importance } \\
\hline Very important & 92.0 & 92.0 & 91.7 \\
\hline Somewhat & 7.6 & 7.5 & 8.3 \\
\hline Not important & 0.4 & 0.5 & - \\
\hline \multicolumn{4}{|c|}{ Behavioral Intentions } \\
\hline Definitely & 19.9 & 20.1 & 18.5 \\
\hline Probably & 35.7 & 35.5 & 37.7 \\
\hline Maybe & 25.4 & 25.0 & 28.5 \\
\hline Probably not & 9.4 & 9.4 & 10.0 \\
\hline Definitely not & 9.5 & 10.1 & 5.4 \\
\hline \multicolumn{4}{|c|}{ Watershed identification } \\
\hline James & 63.2 & 64.4 & 53.8 \\
\hline Upham & 3.7 & 3.0 & 8.3 \\
\hline Other & 6.7 & 7.2 & 3.0 \\
\hline Don't know & 26.5 & 25.3 & 34.8 \\
\hline
\end{tabular}


respondents live (54 linear miles across 23,914 acres), the percentages shown in Table 1 indicate $62.9 \%$ reported they were not aware of any stream or brook in their neighborhood. These percentages were similar in both the impaired and the clean watershed areas; $\chi^{2}$ (2) 1.84 , ns, $n=1,128$.

Appraisal: What condition is the stream or brook in? All respondents who reported that they were aware of the watershed were asked to describe its condition. The majority, 59.4\%, believed that the water was "clean," $30.9 \%$ responded "not clean," and 9\% responded "don't know." These percentages were similar in both the impaired and the clean watershed areas; $\chi^{2}(2)=1.08$, ns, $n=408$.

Importance: How important do you think it is to keep the streams, ditches, and waterways in your area clean and unpolluted? A high value was assigned to clean water: a total of $91.3 \%$ of the respondents reported "very important," with another $7.5 \%$ indicated clean watersheds are "important." Only $0.4 \%(n=5)$ indicated that watershed conservation was not important. These percentages were similar in both the impaired and the clean watershed areas; $\chi^{2}(2)=.771$, ns, $n=1,123$.

Behavioral intentions: Would you be willing to get involved in helping clean up the creeks and streams where you live? Participants expressed positive behavioral intentions pertaining to the watershed, with the mean response of 3.47 (SD = 1.19) falling between the verbal labels of "probably" and "maybe." Over half of the respondents expressed positive behavioral intentions pertaining to watershed protection. Fully $19.5 \%$ of the respondents answered "definitely" and another $34.8 \%$ indicated they "probably" would, and $28.5 \%$ reported that "maybe" they would. A total of $20(9.8 \%)$ respondents reported "probably not," $1.5 \%$ reported "definitely not," and $2.5 \%$ reported "don't know" or did not answer. A one-way ANOVA revealed no differences between the two watersheds; $F(1 ; 1,101)=$ .47 , ns.

Knowledge: When it rains the water runs off the roofs, yards, and streets where you live, into which river does the water flow? The majority, $65.5 \%$, of the residents in the James River Watershed responded correctly when asked to identify the river that carried their runoff water, but a substantial number were uncertain (25.3\%). Relatively few of the residents' of the Upham Brook Watershed, in contrast, identified the correct flow channel. The majority, $54.2 \%$, believed that their runoff went to the James, 34.6\% did not know, $8.3 \%$ correctly recognized that their water flowed to a tributary of the Chickahominy, and $3.2 \%$ had more creative suggestions (e.g., "my neighbor's swimming pool”).

\section{Awareness, Appraisals, and Intentions}

Awareness and appraisal were systematically related to respondents' reported intentions to get involved in watershed cleanup activities. A 3 (awareness of 
watershed: aware, not aware, don't know) X 2 (Watershed: James vs. Upham) ANOVA yielded only a main effect of awareness, with participants who reported they were aware of their watershed expressing more positive behavioral intentions than those who were not aware; $F(2,1098)=8.58, p<.05$. The means were 3.7 and 3.4. A 3 (appraisal: clean, dirty, don't know) X 2 (Watershed: James vs. Upham) ANOVA yielded only a marginally significant main effect of location; $F(1,292)=3.70, p=.055$. Residents of the Upham Brook Watershed expressed more willingness to get involved in a clean up than did residents of the James Watershed. The means were 3.9 and 3.6.

The awareness-appraisal model, however, predicts that individuals who were aware of streams, and who considered those streams to be polluted, would be the most likely to report willingness to get involved in watershed clean up activities. To test this hypothesis, we classified participants into four groups: Those who were unaware of streams in their area, those who were aware and considered the streams clean, those who were aware of streams but did not know their condition, and those who were aware and considered the streams to be dirty. A 4 (awareness/appraisal: clean, dirty, don't know, unaware) X 2 (Watershed: James vs. Upham) ANOVA contrasting these 4 groups revealed the significant differences depicted in Figure 1; $F(3,1092)=5.59, p<.05$. As predicted, those participants who were aware of their watershed features and considered them to be degraded expressed more positive behavioral intentions pertaining to watershed cleanup activities than all other respondents $(p<.05)$. This effect held for both watersheds, although two nonsignificant trends should be noted. First, overall the residents of the Upham Brook Watershed had somewhat more positive behavioral intentions, as noted

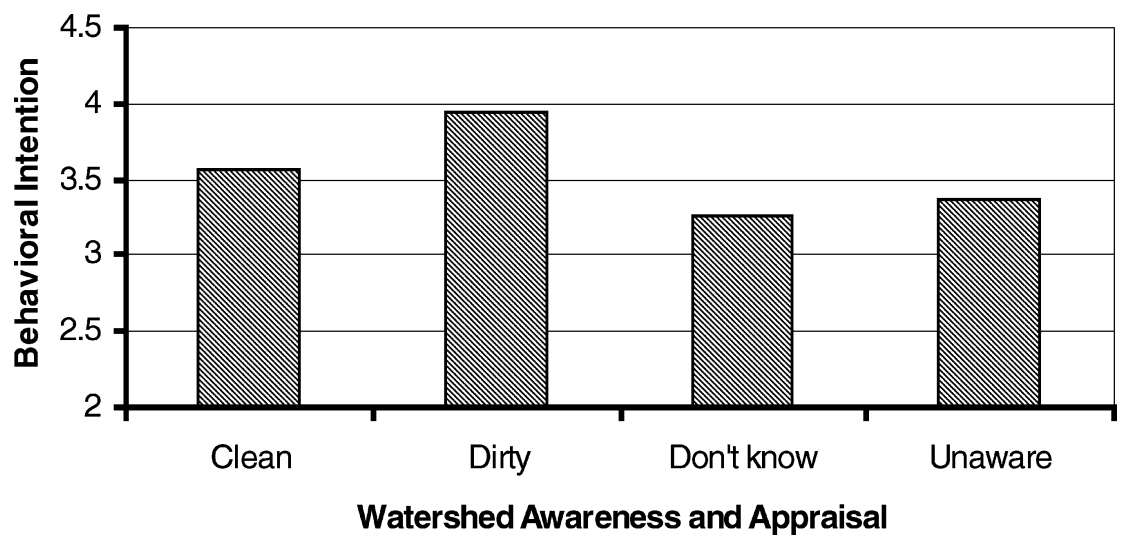

Fig. 1. Mean pro-environment behavioral intentions of four types of residents: (a) those who are aware of their watershed and believe it is clean; (b) those who are aware of their watershed and believe it is dirty; (c) those who are aware of their watershed but do not know its condition; and (d) those who are not aware of their local watershed. 
above; $F(1,1092)=3.00, p=08$. Second, the 4 individuals who reported they were aware of their watershed but not its condition expressed very positive intentions about getting involved in cleaning it up. Their mean was 4.25 , but due to the small number of respondents in this group this difference was neither significant nor interpretable.

\section{Intentions and Values}

The respondents' values pertaining to clean water were correlated with behavioral intentions towards cleaning the watershed, $r=.21, p<.01$. This correlation's magnitude was attenuated by the restriction in range in respondents' reports of the value they place on clean streams. As Table 1 indicates, over $90 \%$ of the respondents believed it was important to keep watershed water clean. A one-way ANOVA comparing the behavioral intentions of participants who differed in the importance that they assigned to clean water reached significance; $F(2,1095)=24.80, p<$ .05. The 1008 respondents who said clean water was very important had more positive intentions than the 85 respondents who rated clean water as important; the means were 3.5 and 2.7. The 5 respondents who reported clean water was not important expressed relatively negative behavioral intentions; their mean was 1.8. Knowledge of streams in the watershed area was also significantly correlated with behavior intentions; $r=.24, p<.01$.

\section{Discussion}

This study of individuals living in an urban area located at the intersection of two large watersheds supported, in general, this cognitive awareness-appraisal model by finding that individuals' intentions to engage in environmentally responsible behavior were related to their awareness of key features of their environment and their evaluation of these features. When we asked residents if they were aware of streams, brooks, and other waterways in their locales, some admitted they were relatively unaware of such water features but others claimed to be well aware of them. Those who were aware of waterways where they lived and considered them polluted were more likely to express pro-preservation behavioral intentions. Thus, awareness alone was not sufficient to trigger a willingness to engage in restorative behaviors-awareness paired with a negative appraisal of the watershed's current state was a better predictor of the promise of pro-environmental involvement than either awareness or appraisal alone.

The results were not specific to the particular watershed where the respondents' resided, even though one of the watersheds we investigated is significantly more degraded than the other. This lack of a difference may result from individuals' inaccuracy when seeking to calibrate their judgments of the severity of an environmental problem, such as watershed pollution. The streams and 
waterways in both watersheds have adequate stream buffers and sustain some aquatic life. The riparian zones surrounding these waterbodies are often thick with vegetation, and the streams have not flooded recently. In consequence, few residents are aware of the condition of the watershed's rivers, streams, and brooks.

These conclusions, based on the quantitative survey, are consistent with the qualitative findings pertaining to residents' awareness of watersheds, in general. The United States Environmental Protection Agency (USEPA) adopted a watershed approach to clean water in the early 1990s. This watershed approach attempts to protect, maintain, and enhance water quality and solve ecosystem problems by focusing on watersheds rather than specific waterbodies or point-discharge sites (USEPA, 1993). This approach's major policy components include (a) the identification of primary threats to human and ecosystem health in watersheds, (b) increased involvement of citizens and other concerned stakeholders in programs designed to protect and enhance watershed quality, and (c) developing, implementing, and evaluating watershed-focused interventions.

Our polling of a representative sample of urban residents' attitudes and behavioral intentions suggests that very few people are familiar with the concept of a watershed or its properties. Few of the respondents who were surveyed initially knew what was meant by the term "watershed," and so the telephone survey focused on waterways located in their neighborhoods rather than the larger watershed area itself. But even when respondents were asked to consider only streams, brooks, ponds, and lakes in their localities, many still reported they were unaware of any such water bodies. Many residents also erred when describing the boundaries of their watersheds. Approximately half of those individuals living in the watershed drained by a series of streams, brooks, and a small river (the Upham Brook watershed area) mistakenly assumed that their runoff water flowed into the James River. Another third of the residents did not know where the water flowed. This lack of knowledge about watersheds is consistent with other studies that have documented the population's general lack of awareness of environmental issues (Bartlett, 1995; Soliman, 1996), but watersheds may be even less visible than other features of the environment. Watersheds include portions of counties and cities, of neighborhoods, industrial and suburban areas, rural and urban areas, and these uncertain boundaries may reduce residents' awareness of them.

The limitations of our findings are substantial, and urge that these findings be interpreted cautiously. Even though we supported predictions derived from the awareness-appraisal model of environmentally positive intentions, the survey methodology we used prevented us from measuring the respondents' actual behavior. Although prior studies of the close relationship between intentions and behavior reported by Ajzen and Fishbein (1980) suggest that our findings pertaining to intentions would generalize to behavior, given the social desirability of pro-environmental action participants may have been overstating their claims of intended restorative action. Indeed, the vast majority of the participants reported 
very favorable attitudes toward the environment, yet a large portion of the respondents had little awareness of the condition of the streams and brooks where they lived. Our correlational design also urges caution in interpreting the findings, for even though we organized our conclusions around a psychological model that suggests awareness and appraisal determine intentions, it may be that individuals who intend to act in an environmentally responsible manner will become more familiar with their environment, as well as justify those actions by revising their appraisal of the environment.

These limitations aside, the current findings lend support to the awarenessappraisal model and suggest ways to promote greater citizen involvement in watershed protection. Like prior work that indicates awareness is a necessary, but not sufficient condition for pro-preservation behavior, the awareness-appraisal model assumes that interventions must not just inform residents about environmental issues. Rather, interventions must go beyond factual presentations by outlining the threats that environmental degradations pose for health, adjustment, and well-being. Ideally, interventions should present the problem as directly affecting the residents thus leading to more positive environmental actions (Baldassare \& Katz, 1992).

Future research should apply these methods to intervention programs and examine the results. Extant literature and this study have only either measured intentions or past behavior. The next logical step is to perform an intervention in the field using the awareness-appraisal model. By applying the information learned through research we can hope to decrease watershed pollution.

\section{References}

Adler, R. W. (1995). Addressing barriers to watershed protection. Environmental Law, 25, $973-$ 1106.

Ajzen, I. \& Fishbein, M. (1980). Understanding attitudes and predicting social behavior. Englewood Cliffs, NJ: Prentice-Hall.

Baldassare, M., \& Katz, C. (1992). The personal threat of environmental problems as predictor of environmental practices. Environment and Behavior, 24, 602-616.

Bartlett, R. A. (1995). Troubled waters: Champion International and the Pigeon River controversy. Knoxville: University of Tennessee Press.

Finger, M. (1994). From knowledge to action? Exploring the relationships between environmental experiences, learning, and behavior. Journal of Social Issues, 50 (3), 141-160.

Folkman, S., \& Lazarus, R. S. (1988). Coping as a mediator of emotion. Journal of Personality and Social Psychology, 54, 466-475.

Gould, K. A. (1993). Pollution and perception: Social visibility and local environmental mobilization. Qualitative Sociology, 16(2), 157-178.

Hungerford, H. R., \& Volk, T. L. (1990). Changing learner behavior through environmental education. Journal of Environmental Education, 21, 8-21.

Kasapoglu, M. A., \& Ecevit, M. C. (2002). Attitudes and behavior toward the environment: The case of Lake Burdur in Turkey. Environment and Behavior, 34, 363-377.

Lazarus, R. S., \& Folkman, S. (1984). Stress, appraisal, and coping. New York: Springer.

Lubell, M. (2002). Environmental activism as collective action. Environment and Behavior, 34(4), $431-454$. 
National Environmental Education and Training Foundation (1999). The 1998 national report card: Environmental knowledge, attitudes and behaviors. Washington, DC: NEETF.

Smith, C. A. (1991). The self, appraisal, and coping. In C. R. Snyder \& D. R. Forsyth (Eds.), Handbook of social and clinical psychology: The health perspective (pp. 116-137). New York: Pergamon.

Soliman, H. H. (1996). Community responses to chronic technological disaster: The case of the Pigeon River. Journal of Social Service Research, 22, 89-108.

US Environmental Protection Agency (USEPA) (1993). The watershed protection approach, Annual Report EPA 84-S-93-001. Washington DC: USEPA.

Van Vugt, M., \& Samuelson, C. D. (1999). The impact of personal metering in the management of a natural resource crisis: A social dilemma analysis. Personality \& Social Psychology Bulletin, $25,731-745$.

Wilson, M. I., Robertson, L. D., Daly, M., \& Walton, S. A. (1995). Effects of visual cues on assessment of water quality. Journal of Environmental Psychology, 15, 53-63.

DONELSON R. FORSYTH is professor of psychology at Virginia Commonwealth University. His interests include group processes, moral decision making, and educational interventions. He is co-principal investigator and team member on the interdisciplinary project "An Integrated Multi-Objective Decision Analysis Model for an Urban Watershed in the Richmond, Virginia, Metropolitan Area," supported by National Science Foundation Grant 9874924 . He received his Ph.D. in social psychology from the University of Florida.

MARGOT W. GARCIA is associate professor emeritus at Virginia Commonwealth University, Wilder School of Government and Policy. She teaches and researches in the area of environmental planning, especially a watershed approach to water quality, and she received her Ph.D. in watershed management from the University of Arizona. She is the principal investigator and leader of an interdisciplinary team of ten researchers studying the James River Watershed in the project "An Integrated Multi-Objective Decision Analysis Model for an Urban Watershed in the Richmond, Virginia, Metropolitan Area."

LINDA E. ZYZNIEWSKI, a social psychologist, received her Ph.D. from Virginia Commonwealth University, where she is currently an assistant professor. She studies group and intergroup processes from an evolutionary perspective and has expertise in multilevel data analysis.

NATALIE A. KERR received her Ph.D. in psychology from Virginia Commonwealth University. She is an assistant professor at James Madison University, where she studies and teaches social psychology and group processes.

PAIL STORY is a Ph.D. candidate in social psychology at Virginia Commonwealth University. He is currently studying approaches to applying social psychological research to solve environmental problems, social traps, and social dilemmas. He received his undergraduate degree in psychology at Arizona State University. 